\title{
Prevalence of Sarcopenia Among the Elderly in Korea: A Meta-Analysis
}

\author{
Yoo Jin Choo, Min Cheol Chang \\ Department of Physical Medicine and Rehabilitation, Yeungnam University College of Medicine, Daegu, Korea
}

Objectives: Sarcopenia is a common disease in the elderly population that causes disability, poor quality of life, and a high risk of death. In the current study, we conducted a meta-analysis to report basic knowledge about the prevalence of sarcopenia in the elderly in Korea. Methods: We searched for articles in the MEDLINE, Cochrane Library, Embase, and Scopus databases published until December 28, 2020. Studies investigating the prevalence of sarcopenia in elderly Koreans aged $\geq 65$ years were included. The methodological quality of the studies was evaluated using the Newcastle-Ottawa scale. Publication bias was evaluated using the Egger test and funnel plots. Results: In total, 3 studies and 2922 patients were included in the meta-analysis. All 3 studies used the European Working Group on Sarcopenia in Older People criteria for the diagnosis of sarcopenia. The total prevalence of sarcopenia was $13.1-14.9 \%$ in elderly men and $11.4 \%$ in elderly women.

Conclusions: This meta-analysis is the first to estimate the pooled prevalence of sarcopenia in elderly Koreans, and its findings suggest that sarcopenia is common in this population. Therefore, attention should be paid to the prevention and control of sarcopenia.

Key words: Sarcopenia, Prevalence, Korea, Meta-analysis

\section{INTRODUCTION}

Sarcopenia refers to a condition wherein the body's muscle mass and strength are abnormally decreased or weakened [1]. It is an age-related disease. In general, $1-2 \%$ of muscle is lost every year starting at the age of 50 years [2]. In older people, sarcopenia is a major problem that causes disability, poor quality of life, and a high risk of death [3]. In Korea, the prevalence of sarcopenia is increasing because of the increase in the el-

Received: January 26, 2021 Accepted: February 24, 2021

Corresponding author: Min Cheol Chang

Department of Physical Medicine and Rehabilitation, Yeungnam

University College of Medicine, 170 Hyeonchung-ro, Nam-gu,

Daegu 42415, Korea

E-mail:wheel633@gmail.com

This is an Open Access article distributed under the terms of the Creative Commons Attribution Non-Commercial License (https://creativecommons.org/licenses/by$\mathrm{nc} / 4.0 /$ ) which permits unrestricted non-commercial use, distribution, and reproduction in any medium, provided the original work is properly cited. derly population and life expectancy [4].

As clinicians' and researchers' interest in sarcopenia has increased, several studies have investigated its prevalence [5-7]. However, the prevalence of sarcopenia has been inconsistent in different studies, and no large-scale epidemiological study of sarcopenia has yet been carried out in Korea.

In the current study, we conducted a meta-analysis and systematically evaluated the prevalence of sarcopenia in elderly Koreans to construct basic data on the prevalence of sarcopenia in Korea.

\section{METHODS}

\section{Search Strategy}

This meta-analysis was conducted in accordance with the PRISMA (Preferred Reporting Items for Systematic Reviews and Meta-Analysis) guidelines [8]. We systematically searched for relevant articles in the PubMed, Embase, Cochrane Library, and 
Scopus databases for studies published up to December 28, 2020. The following keywords were used in the search: (sarcopenia OR muscle mass OR muscle strength) AND (prevalence OR epidemiology OR frequency OR incidence) AND (Korea).

\section{Study Selection}

We applied the following inclusion criteria for the selection of articles: (1) the prevalence rate of sarcopenia was evaluated, (2) the study was conducted among Koreans, (3) age of the included subjects was $\geq 65$ years, and (4) loss of appendicular muscle mass and functional decline were considered for the diagnosis of sarcopenia. The exclusion criteria were (1) the same data published repeatedly, and (2) not reporting study outcomes.

\section{Data Extraction}

After discarding duplicate studies, 2 reviewers (YJC and MCC) independently evaluated the potentially eligible studies. The articles were screened for eligibility by reviewing the title and abstract. Disagreements were resolved through consensus. After screening, the full texts of the eligible articles were read independently by both reviewers, and the eligibility of each article was re-assessed. Subsequently, data on the first author, publication date, study type, number of patients, and demographic characteristics (age, gender, and other participant details) were extracted.

\section{Quality Assessment}

The Newcastle-Ottawa scale (NOS) for cross-sectional studies was used for quality assessment [9], with 3 aspects (selection, comparability, and outcomes). The judgment of bias was expressed as "unsatisfactory," "satisfactory," "good," or "very good." The quality of each study was graded as unsatisfactory (0-4), satisfactory (5-6), good (7-8), or very good (9-10). All differences of opinion were resolved by consensus.

\section{Statistical Analysis}

Using the Comprehensive Meta-Analysis version 2 (Biostat Inc., Englewood, NJ, USA), the extracted data were analyzed using statistical tests. For each analysis, a heterogeneity test was conducted using the $l^{2}$ statistic to evaluate the extent of inconsistency in the obtained results. If the $I^{2}$ value was $>50 \%$, the data were considered to have substantial heterogeneity, and a random-effects model was used for data analysis. In contrast, if the $\mathrm{l}^{2}$ value was $\leq 50 \%$, then the pooled data were considered homogeneous and a fixed-effects model was applied for data analysis. The pooled prevalence and $95 \%$ confidence interval $(\mathrm{Cl})$ of sarcopenia were also calculated.

\section{Ethics Statement}

Ethical approval was waived because this was a meta-analysis based on previously published studies.

\section{RESULTS}

\section{Study Selection}

In total, 721 potentially relevant studies were selected in the preliminary search of all the databases (Figure 1). We excluded 224 duplicate studies and excluded an additional 481 publications after their titles and abstracts were reviewed. The remaining studies were assessed through a review of the full texts of the articles. As a result of full-text screening, 3 articles were included (Table 1) [10-12]. In all 3 articles, the European Working Group on Sarcopenia in Older People (EWGSOP) criteria [13] were used for the diagnosis of sarcopenia.

\section{Study Characteristics}

The selected studies included 2922 patients (male-to-female ratio, 1455:1467). The characteristics of the selected studies are summarized in Table 1.

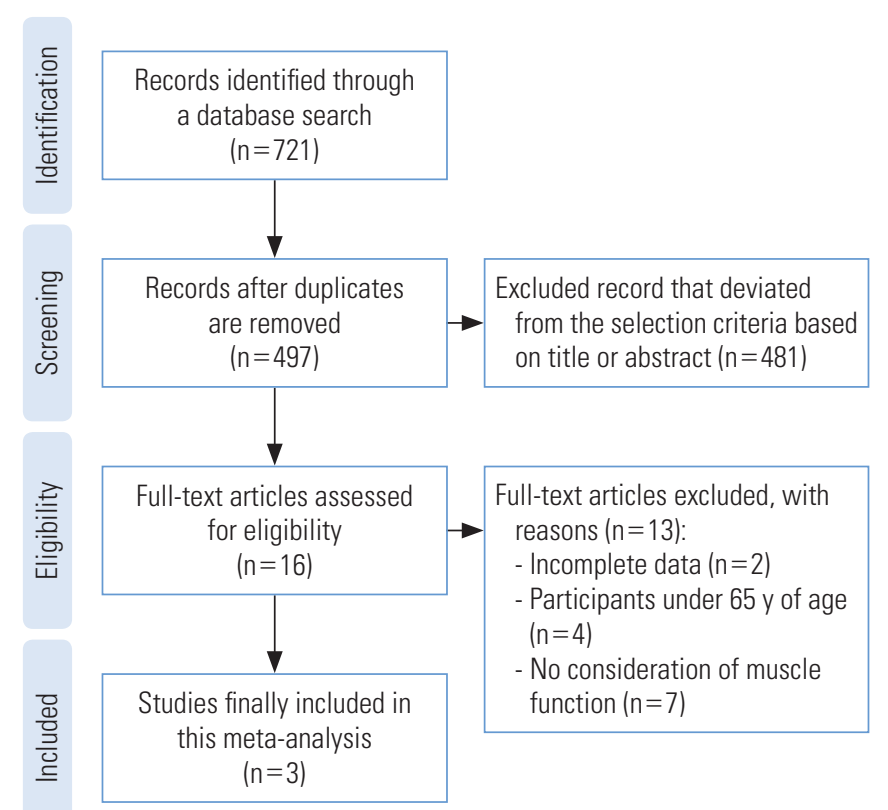

Figure 1. Flow chart showing the search results of the metaanalysis. 
Table 1. Characteristics of the included studies

\begin{tabular}{|c|c|c|c|c|c|c|c|}
\hline Study & Study design & $\begin{array}{c}\text { Subjects } \\
\text { (n, age, M:F) }\end{array}$ & $\begin{array}{l}\text { Definition of } \\
\text { sarcopenia }\end{array}$ & $\begin{array}{l}\text { Body composition } \\
\text { assessment }\end{array}$ & $\begin{array}{l}\text { Muscle function } \\
\text { assessment }\end{array}$ & $\begin{array}{l}\text { Participant recruitment } \\
\text { method }\end{array}$ & Region \\
\hline $\begin{array}{r}\text { Jung et al., } \\
2019[10]\end{array}$ & Cross-sectional & $\begin{array}{l}521,71.6 y, \\
263: 258\end{array}$ & EWGSOP & BIA & Handgrip strength & $\begin{array}{l}\text { National Fitness Award } \\
\text { Project in 2014-2015 }\end{array}$ & Nationwide \\
\hline $\begin{array}{l}\text { Kim et al., } \\
2016 \text { [11] }\end{array}$ & Cross-sectional & $\begin{array}{l}302,75.0 y \\
139: 163\end{array}$ & EWGSOP & DXA & $\begin{array}{l}\text { Handgrip strength, } \\
\text { 6-meter usual gait speed }\end{array}$ & $\begin{array}{l}\text { Hallym Aging Study data in } \\
2010\end{array}$ & Chuncheon \\
\hline $\begin{array}{l}\text { Kim et al., } \\
2019 \text { [12] }\end{array}$ & Cross-sectional & $\begin{array}{c}2099,75.9 y \\
1053: 1046\end{array}$ & EWGSOP & DXA, BIA & $\begin{array}{l}\text { Handgrip strength, chair } \\
\text { stand test (five times } \\
\text { sit-to-stand test) }\end{array}$ & $\begin{array}{l}\text { The nationwide Korean } \\
\text { Frailty and Aging Cohort } \\
\text { Study in 2016-2017 }\end{array}$ & Nationwide \\
\hline
\end{tabular}

M, male; F, female; EWGSOP, European Working Group on Sarcopenia in Older People; BIA, bioelectrical impedance analysis; DXA, dual-energy X-ray absorptiometry.

Total prevalence among elderly people

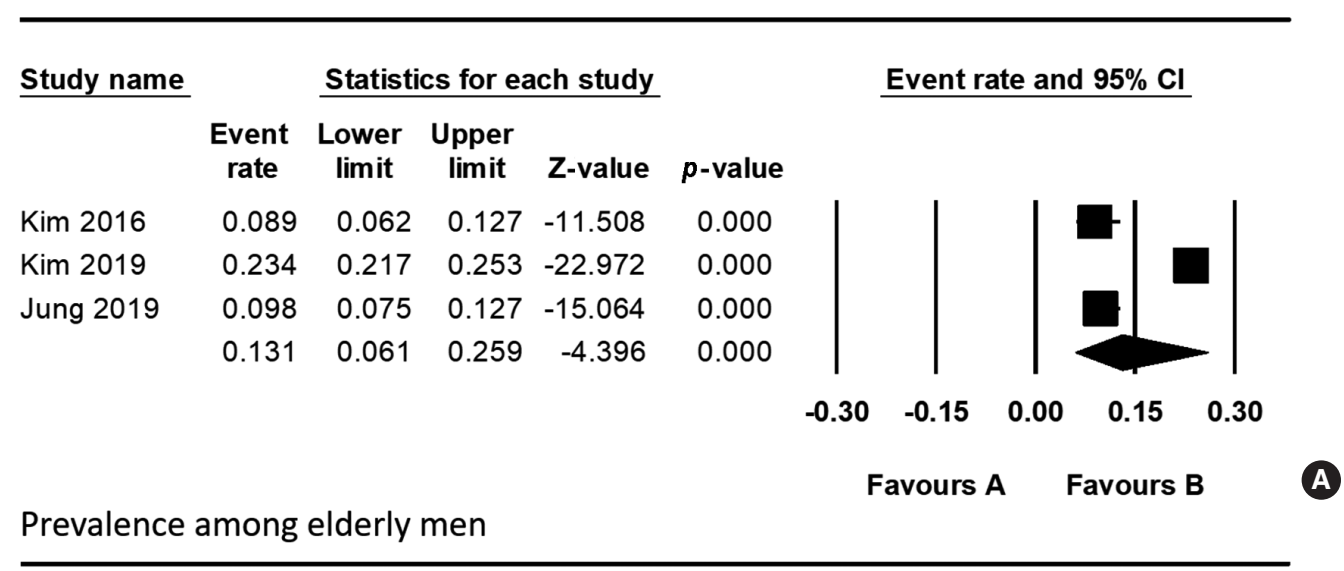

\begin{tabular}{lllllll} 
Study name & \multicolumn{5}{c}{ Statistics for each study } \\
\cline { 1 - 5 } & $\begin{array}{c}\text { Event } \\
\text { rate }\end{array}$ & $\begin{array}{c}\text { Lower } \\
\text { limit }\end{array}$ & $\begin{array}{c}\text { Upper } \\
\text { limit }\end{array}$ & Z-value & $p$-value \\
Kim 2016 & 0.094 & 0.055 & 0.154 & -7.797 & 0.000 \\
Kim 2019 & 0.282 & 0.256 & 0.310 & -13.643 & 0.000 \\
Jung 2019 & 0.110 & 0.078 & 0.154 & -10.606 & 0.000 \\
& 0.149 & 0.063 & 0.315 & -3.548 & 0.000
\end{tabular}

Prevalence among elderly women

Event rate and $95 \% \mathrm{Cl}$

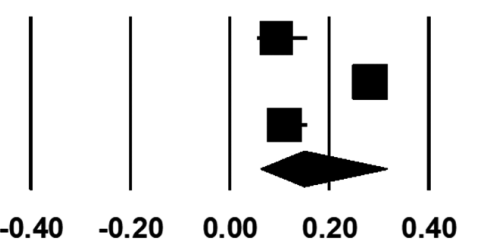

Favours A Favours B

\begin{tabular}{|c|c|c|c|c|c|}
\hline \multirow[t]{2}{*}{ Study name } & \multicolumn{5}{|c|}{ Statistics for each study } \\
\hline & $\begin{array}{l}\text { Event } \\
\text { rate }\end{array}$ & $\begin{array}{l}\text { Lower } \\
\text { limit }\end{array}$ & $\begin{array}{l}\text { Upper } \\
\text { limit }\end{array}$ & Z-value & $p$-value \\
\hline Kim 2016 & 0.086 & 0.052 & 0.140 & -8.460 & 0.000 \\
\hline Kim 2019 & 0.184 & 0.161 & 0.208 & -18.686 & 0.000 \\
\hline \multirow[t]{2}{*}{ Jung 2019} & 0.085 & 0.057 & 0.126 & -10.644 & 0.000 \\
\hline & 0.114 & 0.061 & 0.205 & -5.795 & 0.000 \\
\hline
\end{tabular}

Event rate and $95 \% \mathrm{Cl}$

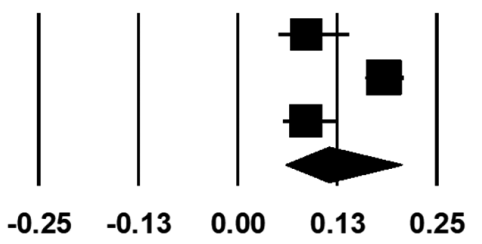

Favours A Favours B 


\section{Risk of Bias}

All the included studies were rated 5 points (selection: 2 points; outcome: 3 points). Therefore, the quality of the 3 studies assessed using the NOS was considered satisfactory.

\section{Meta-analysis Results}

To analyze the prevalence, a random-effects model was used ( ${ }^{2}$ for total prevalence among elderly people, $97.1 \%$; for prevalence among elderly men, 95.8\%; and for prevalence among elderly women, $90.4 \%)$. The total prevalence of sarcopenia among elderly Koreans aged $\geq 65$ years was $13.1 \%(95 \% \mathrm{Cl}$,
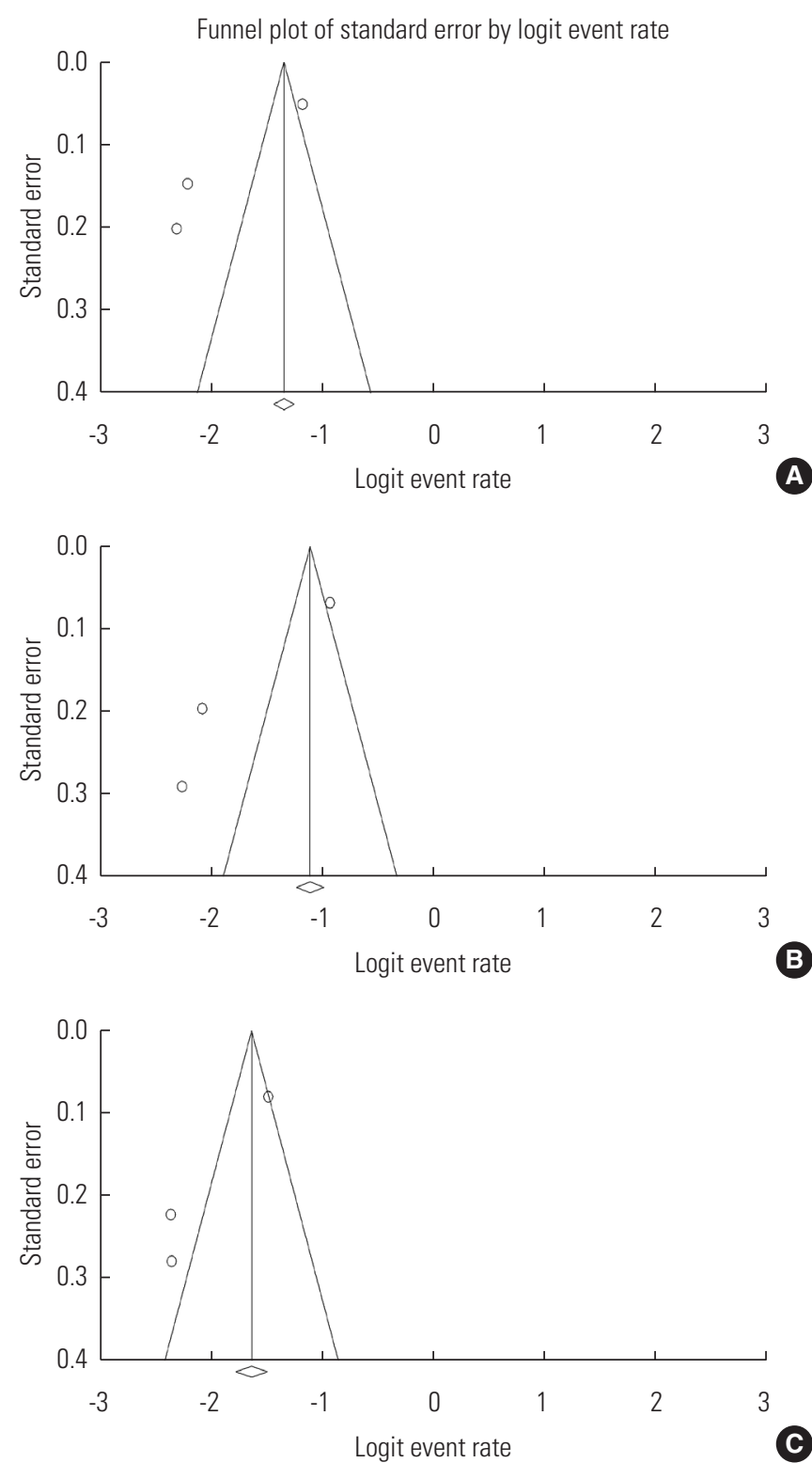

Figure 3. Funnel plots of the included studies (A: total, B: men, C: women).
6.1 to 25.9) (Figure 2). The prevalence of sarcopenia among elderly Korean men was $14.9 \%(95 \% \mathrm{Cl}, 6.3$ to 31.5$)$, whereas the prevalence of sarcopenia among elderly Korean women was $11.4 \%(95 \% \mathrm{Cl}, 6.1$ to 20.5$)$.

\section{Publication Bias}

Funnel plot analysis and the Egger test were performed. Funnel-plot analyses revealed symmetrical results (Figure 3 ). In addition, all $p$-values for the Egger test were $>0.05$ (total prevalence among elderly people: $p=0.301$; prevalence among elderly men: $p=0.069$; prevalence among elderly women: $p=$ 0.059). Therefore, publication bias was not significant.

\section{DISCUSSION}

A meta-analysis was performed to determine the prevalence of sarcopenia in the elderly Korean population. The results showed that the overall prevalence was 13.1\%; the prevalence in men was $14.9 \%$ and that in women was $11.4 \%$. All 3 included studies used the EWGSOP criteria for the diagnosis of sarcopenia.

Although the results of previous studies on the prevalence of sarcopenia are heterogeneous, generally it has been reported to range from $10 \%$ to $20 \%$ [14-17]. Our results are similar to those of previous studies. In addition, in our study, men showed a higher prevalence of sarcopenia than women, which is consistent with the results of several previous studies $[2,18$ 20]. Some possible reasons for this have been suggested. First, the prevalence of sarcopenia increases in patients with diabetes, and since men generally have a higher prevalence of diabetes than women, the prevalence of sarcopenia in men may therefore be higher [21]. Second, a higher prevalence of sarcopenia in men could be related to their higher smoking rate, especially in men in Korea $[5,22]$. Since smoking decreases the amount of blood flow, the amount of oxygen provided to the muscles is reduced. In addition, smoking interferes with normal breathing, and consequently, gas exchange in the lungs cannot be performed normally, which makes it difficult for the muscles to receive oxygen [23]. When muscles are not properly supplied with oxygen, muscle growth is inhibited, which causes sarcopenia. Third, higher alcohol consumption in Korean men could result in a higher prevalence of sarcopenia in men $[14,24]$. It has been reported that alcohol reduces the synthesis of proteins [25]. Since protein synthesis in muscles is an essential factor for muscle growth, excessive alcohol con- 
sumption increases the probability of developing sarcopenia [26]. Thus, stopping or reducing smoking and alcohol consumption in the elderly population would be helpful for preventing and treating sarcopenia. Furthermore, at least 2-4 sessions of combined aerobic exercise and resistance training every week and appropriate protein intake (at least $1 \mathrm{~g} / \mathrm{kg}$ ) are essential for the prevention and treatment of sarcopenia [27].

Regarding the prevalence of sarcopenia in other countries, Du et al. [28] surveyed 2458 elderly individuals ( $\geq 65$ years of age) in the United States and reported that the total prevalence of sarcopenia was $15.51 \%$. Lera et al. [29] reported that the prevalence of sarcopenia in 1006 elderly individuals ( $\geq 60$ years of age) in Santiago, Chile was 19.1\%. Liu et al. [30] investigated the prevalence of sarcopenia in 4500 elderly individuals ( $>60$ years of age) in Yunnan, Guizhou, Sichuan, and Xinjiang in China and found it to be $19.3 \%$. Generally, the prevalence of sarcopenia in Korea is lower than that in other countries. A variety of factors, such as differences in eating habits, the surrounding environment, culture, and race-specific genetics, may be responsible for differences in the prevalence of sarcopenia among countries [31-33].

To date, over a dozen studies have attempted to examine the prevalence of sarcopenia in Korea. However, the 3 studies included in our meta-analysis were the only ones that measured muscle function for the diagnosis of sarcopenia, instead of only considering appendicular muscle mass. Sarcopenia is defined as a condition characterized by loss of both skeletal muscle mass and function. Muscle strength depends on muscle mass, and the relationship between muscle strength and muscle mass is not linear [13]. Therefore, for the diagnosis of sarcopenia, both muscle mass and muscle function must be measured.

\section{CONCLUSION}

We found that the overall prevalence of sarcopenia in the elderly Korean population was $13.1 \%$. The prevalence of sarcopenia in elderly men and women was $14.9 \%$ and $11.4 \%$, respectively. This is the first study to systematically evaluate the prevalence of sarcopenia in Korea through a meta-analysis. However, our study is limited by the inclusion of a small number of studies and population. For more robust results, further well-designed studies with larger populations should be conducted in the future.

\section{CONFLICT OF INTEREST}

The authors have no conflicts of interest associated with the material presented in this paper.

\section{FUNDING}

The present study was supported by a National Research Foundation of Korea grant funded by the Korean government (grant No. NRF-2019M3E5D1A02068106).

\section{ACKNOWLEDGEMENTS}

None.

\section{AUTHOR CONTRIBUTIONS}

Conceptualization: YJC, MCC. Data curation: YJC, MCC. Formal analysis: YJC, MCC. Funding acquisition: MCC. Methodology: YJC, MCC. Visualization: YJC, MCC. Writing - original draft: YJC, MCC. Writing - review \& editing: YJC, MCC.

\section{ORCID}

Yoo Jin Choo https://orcid.org/0000-0002-3820-2279

Min Cheol Chang https://orcid.org/0000-0002-7629-7213

\section{REFERENCES}

1. Walston JD. Sarcopenia in older adults. Curr Opin Rheumatol 2012;24(6):623-627.

2. Tay L, Ding YY, Leung BP, Ismail NH, Yeo A, Yew S, et al. Sex-specific differences in risk factors for sarcopenia amongst community-dwelling older adults. Age (Dordr) 2015;37(6):121.

3. Silva RF, Figueiredo MD, Darder JJ, Santos AM, Tyrrell MA. Sarcopenia screening in elderly in primary health care: nurse knowledge and practices. Rev Bras Enferm 2020;73(Suppl 3): e20200421.

4. Jang HC. How to diagnose sarcopenia in Korean older adults? Ann Geriatr Med Res 2018;22(2):73-79.

5. Kim YS, Lee Y, Chung YS, Lee DJ, Joo NS, Hong D, et al. Prevalence of sarcopenia and sarcopenic obesity in the Korean population based on the Fourth Korean National Health and Nutritional Examination Surveys. J Gerontol A Biol Sci Med Sci 2012;67(10):1107-1113. 
6. Moon JH, Kong MH, Kim HJ. Implication of sarcopenia and sarcopenic obesity on lung function in healthy elderly: using Korean National Health and Nutrition Examination Survey. J Korean Med Sci 2015;30(11):1682-1688.

7. Woo N, Kim SH. Sarcopenia influences fall-related injuries in community-dwelling older adults. Geriatr Nurs 2014;35(4): 279-282.

8. Moher D, Liberati A, Tetzlaff J, Altman DG; PRISMA Group. Preferred reporting items for systematic reviews and meta-analyses: the PRISMA statement. PLoS Med 2009;6(7):e1000097.

9. Luchini C, Stubbs B, Solmi M, Veronese N. Assessing the quality of studies in meta-analyses: advantages and limitations of the Newcastle Ottawa Scale. World J Metaanal 2017;5(4):80-84.

10. Jung M, Park S, Kim H, Kwon O. Association of diet quality with low muscle mass-function in Korean elderly. Int J Environ Res Public Health 2019;16(15):2733.

11. Kim JH, Kim DH, Park YS. Body composition, sarcopenia, and suicidal ideation in elderly Koreans: Hallym Aging Study. J Korean Med Sci 2016;31(4):604-610.

12. Kim M, Won CW. Prevalence of sarcopenia in community-dwelling older adults using the definition of the European Working Group on Sarcopenia in Older People 2: findings from the Korean Frailty and Aging Cohort Study. Age Ageing 2019;48(6): 910-916.

13. Cruz-Jentoft AJ, Baeyens JP, Bauer JM, Boirie Y, Cederholm T, Landi F, et al. Sarcopenia: European consensus on definition and diagnosis: report of the European Working Group on Sarcopenia in Older People. Age Ageing 2010;39(4):412-423.

14. Sun S, Lee H, Yim HW, Won HS, Ko YH. The impact of sarcopenia on health-related quality of life in elderly people: Korean National Health and Nutrition Examination Survey. Korean J Intern Med 2019;34(4):877-884.

15. Kim SH, Kwon HS, Hwang HJ. White blood cell counts, insulin resistance, vitamin D levels and sarcopenia in Korean elderly men. Scand J Clin Lab Invest 2017;77(3):228-233.

16. Kim TN, Lee EJ, Hong JW, Kim JM, Won JC, Kim MK, et al. Relationship between sarcopenia and albuminuria: the 2011 Korea National Health and Nutrition Examination Survey. Medicine (Baltimore) 2016;95(3):e2500.

17. Yoo Jl, Choi H, Ha YC. Mean hand grip strength and cut-off value for sarcopenia in Korean adults using KNHANES VI. J Korean Med Sci 2017;32(5):868-872.

18. Brown JC, Harhay MO, Harhay MN. Sarcopenia and mortality among a population-based sample of community-dwelling older adults. J Cachexia Sarcopenia Muscle 2016;7(3):290-298.
19. Chan R, Leung J, Woo J. A prospective cohort study to examine the association between dietary patterns and sarcopenia in Chinese community-dwelling older people in Hong Kong. J Am Med Dir Assoc 2016;17(4):336-342.

20. Spira D, Norman K, Nikolov J, Demuth I, Steinhagen-Thiessen E, Eckardt R. Prevalence and definition of sarcopenia in community dwelling older people. Data from the Berlin aging study II (BASE-II). Z Gerontol Geriatr 2016;49(2):94-99.

21. Wang T, Feng X, Zhou J, Gong H, Xia S, Wei Q, et al. Type 2 diabetes mellitus is associated with increased risks of sarcopenia and pre-sarcopenia in Chinese elderly. Sci Rep 2016;6:38937.

22. Kim JE, Lee YH, Huh JH, Kang DR, Rhee Y, Lim SK. Early-stage chronic kidney disease, insulin resistance, and osteoporosis as risk factors of sarcopenia in aged population: the fourth Korea National Health and Nutrition Examination Survey (KNHANES IV), 2008-2009. Osteoporos Int 2014;25(9):2189-2198.

23. Benowitz NL, Burbank AD. Cardiovascular toxicity of nicotine: Implications for electronic cigarette use. Trends Cardiovasc Med 2016;26(6):515-523.

24. Kim CR, Jeon YJ, Jeong T. Risk factors associated with low handgrip strength in the older Korean population. PLoS One 2019; 14(3):e0214612.

25. Rom O, Kaisari S, Aizenbud D, Reznick AZ. Lifestyle and sarcopenia-etiology, prevention, and treatment. Rambam Maimonides Med J 2012;3(4):e0024.

26. Lieber CS. Relationships between nutrition, alcohol use, and liver disease. Alcohol Res Health 2003;27(3):220-231.

27. Marcell TJ. Sarcopenia: causes, consequences, and preventions. J Gerontol A Biol Sci Med Sci 2003;58(10):M911-M916.

28. Du K, Goates S, Arensberg MB, Pereira S, Gaillard T. Prevalence of sarcopenia and sarcopenic obesity vary with race/ethnicity and advancing age. Divers Equal Health Care 2018;15(4):175183.

29. Lera L, Albala C, Sánchez H, Angel B, Hormazabal MJ, Márquez $C$, et al. Prevalence of sarcopenia in community-dwelling Chilean elders according to an adapted version of the European Working Group on Sarcopenia in Older People (EWGSOP) criteria. J Frailty Aging 2017;6(1):12-17.

30. Liu X, Hao Q, Yue J, Hou L, Xia X, Zhao W, et al. Sarcopenia, obesity and sarcopenia obesity in comparison: prevalence, metabolic profile, and key differences: results from WCHAT study. J Nutr Health Aging 2020;24(4):429-437.

31. Barbieri E, Agostini D, Polidori E, Potenza L, Guescini M, Lucertini $F$, et al. The pleiotropic effect of physical exercise on mitochondrial dynamics in aging skeletal muscle. Oxid Med Cell 
Longev 2015;2015:917085.

32. Guthold R, Stevens GA, Riley LM, Bull FC. Worldwide trends in insufficient physical activity from 2001 to 2016: a pooled analysis of 358 population-based surveys with 1.9 million participants. Lancet Glob Health 2018;6(10):e1077-e1086.
33. Lee JE, McLerran DF, Rolland B, Chen Y, Grant EJ, Vedanthan R, et al. Meat intake and cause-specific mortality: a pooled analysis of Asian prospective cohort studies. Am J Clin Nutr 2013; 98(4):1032-1041. 